\section{B A Institute of \\ YK Business Administration \\ 六下 \\ Karachi \\ Leadership and Ideas for Tomorrow}

\section{Business Review}

Volume 8 Issue 1 January-June 2013

$1-1-2013$

\title{
An empirical study on weak market efficiency of Karachi Stock Exchange
}

Jaihan Zulqarnain

National Defense University, Islamabad

Syed Muhammad Amir Shah

Allama Iqbal Open University, Islamabad

Follow this and additional works at: https://ir.iba.edu.pk/businessreview

Part of the Finance and Financial Management Commons

(c) (1)

This work is licensed under a Creative Commons Attribution 4.0 International License.

\section{Recommended Citation}

Zulqarnain, J., \& Shah, S. (2013). An empirical study on weak market efficiency of Karachi Stock

Exchange. Business Review, 8(1), 77-84. Retrieved from https://doi.org/10.54784/1990-6587.1217

This article is brought to you by iRepository for open access under the Creative Commons Attribution 4.0 License and is available at https://ir.iba.edu.pk/businessreview/vol8/iss1/6. For more information, please contact irepository@iba.edu.pk. 


\title{
ARTICLE
}

\section{An Empirical Study on Weak Market Efficiency of Karachi Stock Exchange}

\author{
Jaihan Zulqarnain \\ National Defense University, Islamabad \\ Syed Muhammad Amir Shah \\ Allama Iqbal Open University, Islamabad
}

\begin{abstract}
A lot of research has been conducted to check whether the Frontier and emerging markets show weak form of efficiency or follow a random walk. Karachi Stock Exchange, being a frontier market, was tested on the basis of daily closing values from 2006 to 2011. The study showed KSE to be a weak form inefficient market following non randomness. Three tests were applied on the data. KSE proved to have a unit root, the values in the series showed a strong correlation. Moreover, a Z-statistic value was far greater than 1.96 which proved KSE to be an inefficient market. Inefficient markets have several implications for international as well as local investors.
\end{abstract}

\section{Introduction}

Stock market plays a vital role in any financial system. While it contributes to the economics and trade of the country, a strong and an efficient running of the stock markets also play a vital role in benefitting a country's economy. An efficient market is the one that carries unpredictability of future stock prices. In other words, strong form efficiency exists when the stock prices follow a Random Walk and cannot be predicted by any available information in the market, be it in the form of historical data, public news or insider's information.

Weak form efficiency is the one where the prices of the stock fully contain the historical data of the prices. One cannot find out if a stock at a current point in time is undervalued or overvalued hence cannot earn excess returns. If this is absent and the data instead of following a "random walk" exhibits clustering, the market is said to be inefficient.

Generally it has been stated and proved through researches that the developed markets exhibits a random walk and that the efficient market hypothesis holds true for them. Many researchers have found the US and European Markets to be efficient except for a few exceptions. On the other hand, emerging markets are believed to be either weak form efficient or inefficient, if they do not fulfill any of the criteria for market efficiency.

Karachi Stock Exchange is the main representative of the Pakistani Stock Market since it is the oldest, the largest and the most liquid of all the existing ones. A lot of research has been done 
to check the efficiency of KSE, and many have found it to be weak form efficient market while some have found it to be inefficient according to the time periods they have tested. Our study is based on similar studies. We in this research will check the efficiency of the KSE-100 from 2006 to 2011 data and will see if random walk hypothesis holds true for KSE.

\section{Literature Review}

By definition, a market is considered to be efficient when the prices of securities existing in the market are reflecting the available information of the market. In other words, "efficient market" postulates that all the information is assimilated in the prices on which the traders trade the securities. The information in the market might be present in the form of historical data, public news or insider's information.

The efficient market hypothesis, also known as The Random Walk Theory was presented by Fama in the 1960's. It proposed that the market prices fully reflect all the available information and follow a random walk; that one cannot earn excess returns or profits using this information. It suggests that it is very difficult to earn profits by predicting the prices of the securities being traded. (Clarke, Jandik, \& Mandelker, 2001) Moreover, the market is said to be efficient when the prices of the securities regulate quickly to the newly arrived information such that there remains no bias.

Market efficiency is of three types. The market where the investor cannot outperform the market information and cannot earn abnormal or excess returns over the securities with the help of the all the three types of market information is said to be the strong or the most efficient market. Such a type of market is said to follow a random walk. Semi-strong market efficiency is the type where the prices of the securities reflect changes to any public information or news that is floated in the market. The weak form market efficiency is the type where the prices of the traded securities or traded assets reflect and fully contain the historical information of prices. This means that no one can detect the securities that are mispriced; neither can they beat the market by analyzing those prices.(Clarke, Jandik, \& Mandelker, 2001) Such markets are said to follow non randomness and usually reject the Random Walk Hypothesis.

The developed economies have been proved to exhibit the random walk hypothesis. Fama did a very detailed study on New York Stock Exchange in 1965 and proved the validity of the hypothesis especially where it states that the prices changes are random and predictions cannot be made based on the historical price trend. But still many others have rejected it in developed economies. (Mustafa, 2008). A study was done on twenty European markets out of which sixteen were regarded as developed and four were considered to be emerging markets. The authors employed Runs test, ADF as well as multiple variance tests to come to the conclusion that only some countries out of the developed ones (Sweden, Portugal, Ireland, UK and Germany) satisfy the basic criteria of the hypothesis whereas some (Netherlands, Finland, France, Norway and Spain) met only a few requirements of the hypothesis. Hungary was the only country from the emerging markets that satisfied the "strictest requirements for a random walk in daily stock returns." (Worthington \& Higgs, 2003) Worthington and Higgs studies (2003) also concluded that the emerging markets seem to reject the random walk hypothesis. 
The prices of the securities are something that is well known by almost everybody. Hence, it is really difficult to compete and earn profits on the basis of historical price data only. Developing/ emerging and the underdeveloped countries are considered to have a weak-form market efficiency which is usually convenient to test. It is said that emerging markets are characterized by growth potential and rapid business activity (Mobarek \& Keasey, 2000). Samuels (1981) defined the nature of an emerging market as "Prices cannot be assumed to fully reflect all available information. It cannot be assumed that investors will correctly interpret the information that is released. The corporation has greater potential to influence its own stock market price and there is a greater possibility that its price will move about in a manner not justified by the information available." (Samuels, 1981). Hence lower the market efficiency, the ability to predict the changes in stock prices would be greater (Mobarek \& Keasey, 2000).

Roux and Gilbertson (1978), while studying the stock market of Johannesburg found no evidence of a random walk. Instead they found market inefficiency in that emerging market (Roux \& Gilbertson, 1978). Moreover Malaikah (1992) found out that Saudi stock market was inefficient whereas that of Kuwait was efficient (Malaikah, 1990). Ghana Stock Exchange was found to be weakly inefficient, hence rejecting the random walk hypothesis. Clustering was found in the data series which according to the author was an attraction for the investors. Investors seem to invest more when they have the knowledge of the profitable areas and GSE serves the purpose of increasing investors' returns. (Magnus, 2008)

Khababa proposed that Saudi market did not possess weak form efficiency but was inefficient due to the probable reasons like high transaction costs, less market liquidity etc (Khababa, 1998). Dhaka stock Exchange was also found to have weak form efficiency by Alam, Hasan and Kadapakkam in 1999. Kuala Lumpur market was found to be inefficient by Barnes in 1986 (Mustafa, 2008) whereas another research concluded that the KLSE possess weak form efficiency and that there are some pockets that display inefficiencies. (Nassir, Ariff, \& Mohamad, 1993). The studies done by Darat and Zhong in 2000 on two Chinese Stock Exchanges also rejected the market efficiency hypothesis (Darrat \& Zhong, 2000).

Hence the returns are somewhat predictable in the emerging markets and there often exists market inefficiency. The validity of Random Walk theory therefore becomes questionable for the emerging markets.

Several studies have been undertaken to check the Random walk hypothesis and market efficiency of the Pakistani Stock Exchange. Since Karachi Stock Exchange is the oldest and the largest, it has been taken into account by most of the researchers. By using serial correlation test and variance ratios, random walk hypothesis was rejected on the KSE by Chakraborty in 2006. The author took daily closing prices from 1996 to 2000 . KSE was found to be weak form efficient (Chakraborty, 2006). Hameed and Ashraf conducted a research of the similar cause by taking closing prices data from 1998 to 2006 . They rejected the weak form efficiency in KSE and found clusters in the data; hence the data could help in predicting the future values (inefficiency) (Hameed \& Ashraf, 2006). The same results were also given by Haroon in 2006. Khilji in 1994, with his research concluded that Random Walk Hypothesis doesn't define the Pakistani market. (Mustafa, 2008) 
We are going to check the presence of a random walk in the Karachi Stock Exchange from the daily closing values of KSE-100 from 1 July, 2006 to 30 June, 2011.

\section{Hypothesis}

H1: There exists random walk in Karachi Stock Exchange.

\section{Purpose and Methodology}

The main purpose of this study is to check whether Karachi Stock Exchange is a weak efficient market as put down by several researches. For this purpose, we have taken data of KSE100 index's closing values from 1 July, 2006 to 30 June, 2011. The tests that we are applied are the Runs test, the Correlation Tests and the Unit root test with the help of E-views and SPSS.

\section{Results and Analysis}

Augmented Dickey-Fuller's Unit Root Test

According to the Unit root test, greater values of the ADF t-statistic indicate the series to be stationary and the data not having a unit root. Since our study indicates that the ADF t-statistic is lower than the t-statistic of the critical values, our data series is not stationary and has a unit root.

\section{Table - I}

Augmented Dickey-Fuller Test

\begin{tabular}{|c|c|c|c|}
\hline \multirow{2}{*}{\multicolumn{2}{|c|}{ Augmented Dickey-Fuller test statistic }} & t-Statistic & Prob. \\
\hline & & -1.222000 & 0.6669 \\
\hline \multirow[t]{3}{*}{ Test critical values: } & $1 \%$ level & -3.435758 & \\
\hline & $5 \%$ level & -2.863816 & \\
\hline & $10 \%$ level & -2.568032 & \\
\hline
\end{tabular}

The ADF test result of our data indicated that the value lies in the critical region and not in the accepted region. The markets that possess a unit root are the inefficient weak form ones that exhibit non randomness, hence rejecting our hypotheses. Karachi Stock Exchange has no random walk and it is weak form inefficient.

\section{Auto Correlation}

Table 2 shows the auto correlation of the entire sample size. The results show that KSE doesn't follow a random walk. In the Auto Correlation Test all the test values for the KSE-100 touched 0.8 or 0.9 . This proves that each day's price/ value are highly correlated with the previous day's price. Hence, the previous trends can predict the future values. Karachi Stock Exchange is thus, a weak form inefficient market and doesn't follow a random walk (Mustafa, 2008)(Harvey, 
1995, b)(Poshakwale, 1996). These findings are consistent with the studies done by many researchers mentioned. KSE is information ally inefficient market.

Table - II

Auto Correlation

\begin{tabular}{|c|c|c|c|c|c|c|}
\hline \multicolumn{7}{|c|}{$\begin{array}{l}\text { Sample: } 11165 \\
\text { Included observations: } 1165\end{array}$} \\
\hline Autocorrelation & Partial Correlation & & $\mathrm{AC}$ & PAC & Q-Stat & Prob. \\
\hline $\mid * * * * * * * *$ &. $\mid * * * * * * * *$ & 1 & 0.997 & & & \\
\hline $\mid * * * * * * * *$ & $*|\quad|$ & 2 & 0.994 & 0.997 & 1161.5 & 0.000 \\
\hline . $* * * * * * * *$ &. & 3 & 0.990 & -0.113 & 2316.0 & 0.000 \\
\hline. $\mid * * * * * * * *$ &. & 4 & 0.987 & -0.035 & 3463.1 & 0.000 \\
\hline. $\mid * * * * * * * *$ &. & 5 & 0.983 & 0.019 & 4602.8 & 0.000 \\
\hline. $\mid * * * * * * * *$ &. & 6 & 0.979 & -0.047 & 5734.7 & 0.000 \\
\hline.$|* * * * * * *|$ &. & 7 & 0.975 & -0.017 & 6858.4 & 0.000 \\
\hline.$|* * * * * * *|$ &. & 8 & 0.971 & 0.019 & 7974.2 & 0.000 \\
\hline.$|* * * * * * *|$ &. & 9 & 0.967 & -0.012 & 9081.9 & 0.000 \\
\hline.$|* * * * * * *|$ &. & 10 & 0.963 & 0.001 & 10182. & 0.000 \\
\hline.$|* * * * * * *|$ &. & 11 & 0.959 & 0.000 & 11274. & 0.000 \\
\hline.$|* * * * * * *|$ &. & 12 & 0.955 & -0.031 & 12357. & 0.000 \\
\hline.$|* * * * * * *|$ &. & 13 & 0.951 & 0.029 & 13433. & 0.000 \\
\hline.$|* * * * * * *|$ &. & 14 & 0.947 & -0.032 & 14500 & 0.000 \\
\hline.$|* * * * * * *|$ &. & 15 & 0.942 & -0.039 & 15559. & 0.000 \\
\hline.$|* * * * * * *|$ &. $\mid$ & 16 & 0.938 & 0.009 & 16609. & 0.000 \\
\hline.$|* * * * * * *|$ &. & 17 & 0.933 & -0.039 & 17650 & 0.000 \\
\hline.$|* * * * * * *|$ &. & 18 & 0.928 & -0.035 & 18681. & 0.000 \\
\hline.$|* * * * * * *|$ & .1 & 19 & 0.923 & -0.034 & 19702. & 0.000 \\
\hline.$|* * * * * * *|$ & .1 & 20 & 0.918 & -0.014 & 20713. & 0.000 \\
\hline.$|* * * * * * *|$ &. & 21 & 0.913 & 0.003 & 21714. & 0.000 \\
\hline.$|* * * * * * *|$ &. & 22 & 0.908 & 0.003 & 22705 & 0.000 \\
\hline.$|* * * * * * *|$ &. & 23 & 0.903 & 0.010 & 23685 . & 0.000 \\
\hline.$|* * * * * * *|$ &. & 24 & 0.898 & 0.017 & 24656. & 0.000 \\
\hline.$|* * * * * * *|$ & .1 & 25 & 0.894 & 0.026 & 25617. & 0.000 \\
\hline.$|* * * * * * *|$ & .1 & 26 & 0.890 & 0.030 & 26570 . & 0.000 \\
\hline.$|* * * * * * *|$ & .1 & 27 & 0.885 & 0.031 & 27515 . & 0.000 \\
\hline.$|* * * * * * *|$ & .1 & 28 & 0.881 & -0.021 & 28451. & 0.000 \\
\hline.$|* * * * * * *|$ & .1 & 29 & 0.877 & 0.010 & 29379. & 0.000 \\
\hline.$|* * * * * * *|$ & .1 & 30 & 0.872 & -0.012 & 30298. & 0.000 \\
\hline.$|* * * * * * *|$ & .1 & 31 & 0.868 & -0.001 & 31210 . & 0.000 \\
\hline.$|* * * * * * *|$ &. $\mid$ & 32 & 0.863 & -0.021 & 32113. & 0.000 \\
\hline$|* * * * * * *|$ &. & 33 & 0.859 & 0.009 & 33007. & 0.000 \\
\hline.$|* * * * * * *|$ & .1 & 34 & 0.855 & 0.011 & 33894. & 0.000 \\
\hline.$|* * * * * * *|$ &. & 35 & 0.850 & -0.007 & 34772 . & 0.000 \\
\hline.$|* * * * * * *|$ & .1 & 36 & 0.846 & -0.010 & 35642 . & 0.000 \\
\hline & & & & -0.021 & 36504. & 0.000 \\
\hline
\end{tabular}




\section{Runs Test}

Runs Test is used to check the randomness in the series of data. This is to check whether the data series follow a random walk or not (Mustafa, 2008). When the expected number of runs varies largely from the observed number of runs, the test will reject the hypothesis that the series follow a random walk hypothesis.

From the Runs Test, Karachi Stock Exchange is proved to be a weak form inefficient market. Since a $Z$ value greater than 1.96 represents non randomness, the value as indicated by the SPSS test shows weak form efficiency.

Table - III

Runs Test

\begin{tabular}{lr}
\hline & KSE \\
Test Value $^{\mathrm{a}}$ & 10619.00 \\
Cases $<$ Test Value & 582 \\
Cases $>=$ Test Value & 583 \\
Total Cases & 1165 \\
Number of Runs & 28 \\
Z & -32.564 \\
Asymp. Sig. (2-tailed) & .000 \\
\hline a. Median &
\end{tabular}

\section{Conclusion \& Discussion}

This study was conducted to check the market efficiency of Karachi Stock Exchange. Data on daily basis was taken for five years. The data was put to test using Unit root test, Auto correlation as well as Runs test using E-views and SPSS software. The results of all three tests proved Karachi Stock Exchange to be following non randomness and rejecting the random walk hypothesis. The Auto Correlation results showed that there is more than $80 \%$ correlation between the prices. This leads to inefficiency as the future prices can be predicted using the previous days' prices. Similarly the null hypothesis for the Dickey Fuller test was accepted. KSE has a unit root hence it is inefficient. Moreover, a greater $\mathrm{Z}$ value in the Runs test proved KSE to be nonrandom hence weak form inefficient.

Karachi Stock Exchange being a frontier market is a weak form inefficient market and rejects the random walk hypothesis i.e. the prices cannot be predicted by the past prices in this market. The prices do not fully reflect the available information hence there are chances that the investor might attain access to abnormal returns. Efficient markets are a necessary prerequisite if a country wants its money to be invested on the important high- value projects (Hameed \& Ashraf, 2006). 
There can be various implications for such results. Investors can work on the over or undervaluation of the stock prices to earn the abnormal returns. Hence, such markets are usually considered attractive for investors. According to Samuels and Yacout (1981):

"...there are priori reasons to believe that stock markets in developing countries are neither efficient nor perfect. If a stock market is not efficient, this does not necessarily mean that per se it is a bad thing. The crucial question is whether an inefficient stock market is better than no market at all. "Further researches can be done by taking a larger data series to cater a wider time span.

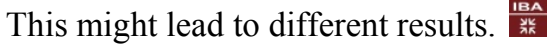

\section{References}

Chakraborty, M. (2006). Market Efficiency for Pakistan Stock Market: Evidence from Karachi Stock Exchange. South Asia Economic Journal, 7 (1), 67-81.

Clarke, J., Jandik, T., \& Mandelker, G. (2001). The Efficient Market Hypothesis. Expert Financial Planning: Investment Strategies from Industry Leader .

Darrat, A. F., \& Zhong. (2000). On Testing the Random-Walk Hypothesis: A Model Comparison Approach. The Financial Review, 35 (3), 105-124.

Gujarati, D. N. (1988). In “Basic Econometrics” (2 ed., p. 691). Mcgraw Hill Book \ company.

Hameed, A., \& Ashraf, H. (2006). Stock Market Volatility and Weak-Form Efficiency: Evidence From an Emerging Market. The Pakistan Development Review., 45 (4), 10291040 .

Harvey, C. R. (1995, b). Predictable Risk and Returns in Emerging Markets. The Review Of Financial Studies, 8 (3), 773-816.

Khababa, N. (1998). Behavior of Stock Prices in the Saudi Arabian Stock Market: Empirical Research Findings. Journal of Financial Management and Analysis, 11 (1), 4855.

Magnus, F. J. (2008). Capital Market Efficiency: An Analysis of Weak-form Efficiency on the Ghana Stock Exchange. Journal of Money, Investment and Banking (5), 5-12.

Malaikah, S. (1990). Saudi Arabia and Kuwait: A study of Stock Market Behavior and Its Policy Implication. Michigan State University, USA.

Mobarek, A., \& Keasey, K. (2000). Weak-form market efficiency of an emerging Market: Evidence from Dhaka Stock Market of Bangladesh. ENBS Conference. Oslo.

Mustafa, K. (2008). Role of Information on Stock Market. IBA, Karachi.

Nassir, A., Ariff, M., \& Mohamad, S. (1993). Weak-Form Efficiency of The Kuala

Lumpur Stock Exchange: An Application of Unit Root Analysis. PertanikaJ. Soc. Sci. \& 
Hum., 1 (1), 57-62.

Poshakwale, S. (1996). Evidence on the Weak-Form Efficiency and The Day of the Week Effect in the Indian Stock Market. Finance India, 10 (3), 605-616.

Roux, \& Gilbertson. (1978). The Behavior of Stock Prices on the Johannesburg Stock Exchange. Journal of Business, Finance and Accounting, 5 (2), 223-232.

Samuels, J. a. (1981). Stock Exchanges in Developing Countries. Savings and Development, 4.

Worthington, A., \& Higgs, H. (2003). Weak-form market efficiency in European emerging and developed stock markets. Brisbane, Australia: School of Economics and Finance Discussion Papers and Working Papers Series .

"The emergence of management, as an essential, a distinct and a leading institution is a pivotal event in social history, Rarely if ever, has a new basic institution, a new leading group emerged as fast as has management since the turn of this century. Rarely in human history has a new institution proven in dispensable so quickly and even less often has a new institution with so little opposition, so little disturbance, and so little controversy."

Petter F. Drucker Rumi 